\title{
вмJ Global Health Governing multisectoral action for health in low-income and middle- income countries: unpacking the problem and rising to the challenge
}

\author{
Sara Bennett, ${ }^{1}$ Douglas Glandon, ${ }^{1}$ Kumanan Rasanathan ${ }^{2}$
}

\begin{abstract}
To cite: Bennett S, Glandon D, Rasanathan K. Governing multisectoral action for health in low-income and middleincome countries: unpacking the problem and rising to the challenge. BMJ Glob Health 2018;3:e000880. doi:10.1136/ bmjgh-2018-000880
\end{abstract}

Handling editor Seye Abimbola

Received 9 April 2018

Revised 7 September 2018

Accepted 10 September 2018

Check for updates

(c) Author(s) (or their employer(s)) 2018. Re-use permitted under CC BY-NC. No commercial re-use. See rights and permissions. Published by BMJ.

'Department of International Health, Johns Hopkins Bloomberg School of Public Health, Baltimore, Maryland USA

${ }^{2}$ Health Section, UNICEF, New York City, New York, USA

Correspondence to Professor Sara Bennett; sbennett@jhu.edu

\section{ABSTRACT}

Multisectoral action is key to addressing many pressing global health challenges and critical for achieving the Sustainable Development Goals, but to-date, understanding about how best to promote and support multisectoral action for health is relatively limited. The challenges to multisectoral action may be more acute in low-income and middle-income countries (LMICs) where institutions are frequently weak, and fragmentation, even within the health sector, can undermine coordination. We apply the lens of governance to understand challenges to multisectoral action. This paper (1) provides a high level overview of possible disciplines, frameworks and theories that could be applied to enrich analyses in this field; (2) summarises the literature that has sought to describe governance of multisectoral action for health in LMICs using a simple political economy framework that identifies interests, institutions and ideas and (3) introduces the papers in the supplement. Our review highlights the diverse, but often political nature of factors influencing the success of multisectoral action. Key factors include the importance of high level political commitment; the incentives for competition versus collaboration between bureaucratic agencies and the extent to which there is common understanding across actors about the problem. The supplement papers seek to promote debate and understanding about research and practice approaches to the governance of multisectoral action and illustrate salient issues through case studies. The papers here are unable to cover all aspects of this topic, but in the final two papers, we seek to develop an agenda for future action. This paper introduces a supplement on the governance of multisectoral action for health. While many case studies exist in this domain, we identify a need for greater theory-based conceptualisation of multisectoral action and more sophisticated empirical investigation of such collaborations.

\section{INTRODUCTION}

While it has long been recognised that influences on human health are many and complex and are often rooted in contexts over which Ministries of Health have very limited control, tackling the multisectoral nature of human

\section{Summary box}

- Multisectoral action for health is key to achieving the Sustainable Development Goals, but to-date our understanding of how to manage effective actions across sectors is partial at best.

- While multisectoral actions for health differ across different health issues and conditions, they all require strong governance, that is, mechanisms and processes through which different actors 'articulate their interests, exercise their rights and obligations, and mediate their differences'.

- A much stronger understanding of the political economy of multisectoral action is needed including investigating how ideas, institutions and interests influence the outcome of multisectoral action.

- More sophisticated approaches to research are needed, including better conceptual frameworks and theories, alongside stronger metrics and empirical analysis, so as to better understand how to support effective multisectoral action.

health challenges appears increasingly central to the development agenda. ${ }^{2}$ The Sustainable Development Goals (SDGs) underscore this point, identifying how non-health goals may lead to health gains. ${ }^{3} 4$ From promoting early childhood health and development, to addressing the challenge of non-communicable diseases, controlling emerging zoonotic and vectorborne diseases, reducing injuries, addressing malnutrition-all of these pressing public health problems require establishing and sustaining collaborations across functional sectors, such as health, agriculture, education, social welfare, trade and industry and environment.

The history of global health is replete with declarations, charters and commissions that have emphasised the importance of multisectoral approaches to improve human health (see box 1), often with the perspective of the need to address the social determinants of health. ${ }^{56}$ 
Box 1 Milestones in attempts to promote multisectoral action in Global Health

- The International Sanitary Conference 1851

- Declaration of Alma Ata (1978).

- Ottawa Charter (1986).

- Commission on Social Determinants of Health (2005-2008).

- Health in All Policies approach (2007-with Adelaide Statement in 2010 and Helsinki Statement in 2013).

Agenda 2030 for Sustainable Development (2015).

There have been some highly successful and visible multisectoral initiatives to improve health in low-income and middle-income countries (LMICs), including, for example, reductions in maternal and child health inequities in Latin America through multisectoral cash transfers, early childhood development and improved healthcare systems; ${ }^{78}$ tobacco control measures notably the Framework Convention on Tobacco Control ${ }^{9}$ and road safety initiatives. ${ }^{10}$ But while multisectoral action is widely recognised as imperative to reach health targets and improve health outcomes, it has frequently proven very difficult to implement and there are perhaps many more, less well documented initiatives, where collaboration has not delivered the anticipated gains or has failed altogether. ${ }^{21}$

This supplement focuses on the governance of multisectoral action for health. What do we mean by this and why have we chosen this focus rather than other possible approaches to thinking about strengthening multisectoral action? Governance has been defined in many ways. At its broadest, the United Nations Development Program defines it as: 'the exercise of political, economic and administrative authority at all levels, to manage a country's affairs. ${ }^{12}$ The WHO's definition is richer, providing more detail about the processes involved in governance, arguing that governance encompasses the complex mechanisms, processes, relationships and institutions through which citizens and groups articulate their interests, exercise their rights and obligations, and mediate their differences'.13 De Leeuw adapts this definition to intersectoral governance, articulating it as: 'the sum of the many ways in which individuals and institutions, public and private, manage the connexions of their common affairs. It is a continuing process through which conflicting or diverse interests may be accommodated and cooperative action may be taken.'

We believe that governance is an appropriate lens to apply to study multisectoral action as it fundamentally concerns the processes through which different groups, both public sector organisations (from different functional sectors and different levels of jurisdiction-federal, state, local) and private sector entities including corporations and citizens' groups, interact to shape public health including social determinants of health as well as health-relevant services. At its core, multisectoral action requires the mediation of relationships and alignment of goals between multiple diverse actors who may share some common interests but have distinct mandates, values and resources. Thus, multisectoral action requires effective governance: it requires approaches to facilitate dialogue and negotiation across different actors, organisations and sectors that involve the recognition and (potentially) reconciliation of conflicting positions, the identification of shared goals as well as deliberations around resource use, reporting and accountabilities. Often the literature, both in public health and in the field of public administration, ${ }^{1415}$ emphasises the notion of collaboration and implicitly assumes a degree of consensus and common interest among actors. However, there has been significant recent attention to the many conflicts of interest that permeate the public health domain, from tobacco, to alcohol to nutrition, ${ }^{16-18}$ and efforts to appropriately address these concerns also require careful governance.

The premise for our original meeting at the Rockefeller Foundation Bellagio Center, and then this supplement that stems from the meeting, was that while within global health, there is a growing interest in multisectoral collaboration, too frequently this is approached through specific disease or service siloes (eg, One Health, or nutrition services or non-communicable diseases), and the governance of multisectoral collaborations is a byproduct of such analyses, rarely forming the central focus of attention. There are two corollaries of this. First, it is uncommon for the global health community to think broadly about the kind of capacities that are needed to develop, manage and sustain multisectoral collaborations, including, for example, the implications for training of public health experts or institutional structures. Second, much of the global health literature on multisectoral collaboration is atheoretical and makes little use of relevant frameworks and theories in the broader literature. Our purpose in this introductory paper is to (1) illustrate the diversity of possible disciplines, frameworks and theories that could be applied to enrich analyses in this field; (2) provide a high-level overview of the type of literature available on the governance of multisectoral action for health in LMIC and (3) introduce the papers in the supplement. Throughout the paper, we use the terms global health, global health governance, global health policy and so on. In using these terms, our focus is primarily on LMIC, acknowledging the shortcomings of this classification and the immense heterogeneity within countries classified as such. There is a significant (and in some respects global) literature on the governance of multisectoral collaborations in high-income countries. We hope that this supplement, along with other efforts, can inform thinking in lower resource environments.

\section{SPECIAL CONSIDERATIONS FOR LOW-INCOME AND MIDDLE- INCOME COUNTRIES}

While much of the academic literature on multisectoral governance comes from high-income countries, many LMIC often face different, more challenging, conditions. ${ }^{19}{ }^{20}$ They may have weak public institutions, including government departments that suffer from limited funding, low salaries and relatively few skilled staff. Multisectoral 
action requires engagement across organisational boundaries, but this may be challenging in LMIC bureaucratic contexts where there is frequently unclear delineation of roles and responsibilities, and complex and sometimes overlapping accountabilities. ${ }^{20}$ Such problems may be compounded by contextual factors such as corruption and patronage which distort official accountabilities and incentives, and can lead to perverse, unpredictable outcomes. ${ }^{21}$

In many LMIC, there has been limited modernisation or innovation in public administration. Ministries of Health are still typically highly hierarchical organisations that emphasise authority, responsibility and loyalty but fail to promote horizontal communication or partnership. Due in part to the weakness of the state, but also in line with what has been seen in high-income countries, there has often been a proliferation of 'public/private partnerships' in global health, promoted in part by external aid agencies. ${ }^{22}$ In many instances, LMIC governments have found this kind of public/private collaboration, that may form a frequent part of multisectoral collaborations, difficult to manage. ${ }^{23}$

It is also worthwhile reflecting on the legitimacy and power of government vis a vis other actors in LMIC contexts. In some cases, national governments suffer from weak capacity and limited legitimacy potentially in the eyes of their electorate and also externally with other governments or international actors. Further, sometimes, particularly in aid-dependent countries, development partners can play an outsize role in shaping policy and practice. To give one relevant example, while multisectoral initiatives require collaboration across boundaries, many LMIC health sectors suffer a high degree of internal fragmentation and this can be particularly problematic in aid-dependent countries where development partners may fragment health systems along geographic or programme lines. ${ }^{24}$

\section{RELEVANT DISCIPLINES, THEORIES AND FRAMEWORKS}

There are multiple disciplines, theories and frameworks through which we might investigate the governance of multisectoral action for health. In recent years, the field of public administration has paid significant attention to multisectoral collaboration. Early work in this domain was often driven by government initiatives, such as those in the UK, Australia and New Zealand that sought to ensure greater policy and implementation coherence across different levels and sectors of government, in part with an eye to enhancing efficiency. ${ }^{25}{ }^{26}$ These initiatives were often referred to as 'joined-up government' and 'whole of government' approaches. Much of the joined-up government literature focuses on the mechanics of collaboration, for example, the type of budgetary arrangements, committee structures and reporting channels that can support interagency collaboration.

Bryson et $a l^{27}$ argue that more recently, approaches to multisectoral governance have further evolved, in particular so as to respond to increasingly important 'wicked' problems such as natural disasters, deepening inequality and failing health systems. The hallmark of such approaches, often referred to as collaborative governance, is recognition of the need to work with multiple organs of government and to collaborate with non-governmental sectors, including affected populations. This literature on collaborative governance emphasises iterative processes that typically involve multiple stakeholders so as to help build common understandings, shared goals and rules of engagement. Specific frameworks for analysing collaborative governance have been proposed, including an influential one by Ansell and Gash, ${ }^{15}$ recently revised and expanded by Emerson and Nabatchi ${ }^{28}$ (see below). This body of literature is almost entirely focused on high-income contexts.

While public administration has perhaps made the most significant contribution to thinking about the governance of multisectoral collaborations, there are other possible approaches. For example, driven initially by work at the World Bank that underlined the importance of 'good governance' to development outcomes, ${ }^{29}$ there has been growing interest in governance approaches within and beyond the health sector. As noted previously, this literature on 'governance' extends beyond the role of government so as to consider multiple actors and the institutional arrangements in place to help achieve common goals. ${ }^{30}$ Within the health sector, analysts have sought to understand the different dimensions of governance,,${ }^{31}$ and how governance actually operates within LMIC health systems. ${ }^{3233}$ But while European publications have sought to address the specific needs of governance related to multisectoral collaboration, ${ }^{34}$ frameworks and analyses focused on LMIC are often yet to encompass this. There is also a related body of work on global health governance that has sought to understand how prepared global institutions are to respond to the emerging health challenges associated with globalisation $^{36-38}$ and specifically the social determinants of health. ${ }^{39}$ As many challenges of globalisation are multisectoral, this literature inevitably asks questions concerning coordination across multiple bodies with different mandates, raises issues regarding the relative power of different actors and interrogates how institutions-from international treaties to informal norms-influence governance.

Finally, political economy may also provide a relevant lens for analysing multisectoral collaboration. The field is fundamentally concerned with the power and interests of different actors (both individuals and organisations), and how institutional structures, from formal laws to informal cultural norms, shape their behaviour. As illustrated in box 2, multisectoral action for health may encompass situations where there is relatively strong alignment of interests of participating actors, all the way through to situations where actors face competing interests. Analysing the interests of different actors as well as the strength and nature of power that they bring to negotiations over multisectoral issues and the institutions which these negotiations work through may therefore help us to understand the challenges to more effective governance of multisectoral action. While there are multiple possible frameworks for thinking about political economy (such as Public Choice 


\section{Box 2 What do we mean by multisectoral action for} health?

'Multisectoral action for health' encompasses all activities involving non-health sector actors that can potentially improve health. This may include:

- Spillover effects for health: actors in non-health sectors undertake their core business (such as educating children) but there are positive effects for health, and this may or may not involve explicit collaboration with health sector actors.

- Cross-sectoral policies: coordinated policies across different sectors to address structural forces and social norms that may affect particular vulnerable groups or society as a whole. This includes many examples of coordinated social policies addressing disparities, but which also deliver benefits for health through addressing social determinants.

- Health sector led collaborations for health: an actor within the health sector collaborates with one or more other partners to directly deliver benefits for health, for example, promoting tobacco taxation or reducing environmental pollution.

'Multisectoral action for health' encompasses the movement for 'intersectoral action' that arose from the Declaration of Alma Ata, but is broader in that it explicitly recognises spillover effects where there is not necessarily any coordination between sectors or coordination by the health sector.

theory, Elinor Ostrom's Institutional Analysis and Development Framework ${ }^{40}$ or Applied Political Economy ${ }^{41}$ ) in the next section, we employ a relatively simple framework derived from work by Peter Hall ${ }^{42}$ and widely employed in the literature that distinguishes between:

- Interests: the motivations for different actors in engaging with a particular issue, their relative power and the sources of power that they draw on to influence outcomes.

- Institutions: how established institutions, including broader legal contexts, bureaucratic arrangements that govern relationships between different public sector entities and organisational capacity (within government and without) influence multisectoral collaboration.

- Ideas: how the framing of societal problems, policy solutions and the evidence that supports them influence actors, in particular their ability to identify with common goals.

We use this simple framework to map some of the challenges that have been identified in terms of governing multisectoral collaboration for health in LMIC.

\section{CHALLENGES IN GOVERNING MULTISECTORAL ACTION: INTERESTS, INSTITUTIONS AND IDEAS Interests}

The literature from LMIC points to a number of different reasons why multisectoral action for health appears on policy agendas and the actors responsible for putting it there. Both actors and the motivations involved differ for different types of health conditions. Disease outbreaks, particularly of zoonotic diseases, often trigger multisectoral action for health. In Uganda, a severe trypanosomiasis outbreak in 1998 that required an integrated approach to be brought under control ${ }^{43}$ created concern at very high levels, including the prime minister's office, and led to the establishment of the Co-ordinating Office for the Control of Trypanosomiasis (COCTU). While the establishment of COCTU in the wake of the outbreak was executed through support from powerful actors (the prime minister's office and an act of parliament), COCTU subsequently struggled to maintain political and financial support. Similarly, in Nigeria, an H5N1 (avian influenza) outbreak on a commercial poultry farm led to high level political concern and government willingness to invest in multisectoral action which in turn led to several institutional developments; however, in this case, perhaps due to the nature of the original outbreak, the Ministry of Agriculture was highly supportive, but the Ministry of Health was less so. ${ }^{43}$

Case studies in both Brazil and the Philippines describe the importance of high level political focus for nutrition. In Brazil, it has been argued that the 1988 constitution that focused on hunger and poverty alleviation helped incentivise a more integrated approach to nutrition, ${ }^{44} 45$ but Acosta suggests that President Lula's active personal support, and a presidential strategy to coordinate ministerial support, as well as sustained civil society demand for effective nutrition strategies were critical to success. ${ }^{45} \mathrm{In}$ the Philippines, the 1974 Nutrition Act was viewed as being critical to the development of multisectoral approaches for nutrition. The Act also established the National Nutrition Council whose governing board is 'composed of 10 of the President's cabinet members and 3 private-sector representatives appointed by the President' ${ }^{46}$ Beyond this influential government body, nutrition action in the Philippines has also involved consciousness raising at every level of government to maintain support for nutrition initiatives.

With respect to the development of initiatives to address non-communicable diseases, there is often clear opposition to such policies from the food, tobacco or alcohol industries. ${ }^{17}$ In the tobacco field where significant progress has been made, strong initiating leaders appear to have been key. ${ }^{47}$ In Turkey, active policy entrepreneurs from civil society, together with high level political pressure linked to Turkey's aspiration to join the European Union played a central role. ${ }^{47}$ in Brazil, strong leadership, initially from activists outside of government helped stimulate action, and this was later carried forward by strong leadership within government. ${ }^{48}$ Strong leadership was also present in Michael Bloomberg's efforts to tackle obesity in New York and Gro Bruntland's stewardship of the Framework Convention on Tobacco Control at the WHO.

Emerson and Nabatchi's framework ${ }^{28}$ contrasts collaborations that come about through the voluntary association of stakeholders versus those which are more externally imposed. In LMIC, a related factor concerns the role of external development partners. Multisectoral action that has strong external support likely has better access to financial resources, but may suffer from limited local ownership (and hence perhaps low motivation), and conceivably 
organisational blue prints that do not align with ways of doing business in country. Such challenges were clearly present in a case study of the One World-One Health approach in Uganda. ${ }^{49}$

Public choice theory suggests that bureaucrats, besides serving the public good, may also seek to maximise the budgets and/or staff that they control. These types of behaviours may inhibit the establishment of successful collaboration dynamics for multisectoral action. For example, implicit hierarchies between different government agencies, or the professions within them can seed unwillingness to collaborate, or rivalries between agencies that may lead to unproductive bureaucratic competition. ${ }^{50}$ Such rivalries may be exacerbated if two different agencies are effectively competing with each other over budgetary allocations. ${ }^{51}$ Sometimes collaborations may also entail supervisory or hierarchical relationships between agencies, for example, where one agency is given responsibility of monitoring and holding accountable other agencies. Such relationships may be seen as a diminution of power on the part of the overseen agency and also resisted. Emerson and $\mathrm{Nabatchi}^{28}$ argue that strong collaborative governance entails the appropriate representation of diverse affected stakeholders. For HIV/AIDS, for example, this would include key populations and affected communities. Some government actors may resist the notion of bringing such groups into policy and decision making, perhaps through fear of a dilution of their own power, as well as risk averseness.

\section{Institutions}

It has been argued that multisectoral action is likely to be more challenging when organisational structures are weak, for example, lacking clear goals and lines of authority. ${ }^{52}$ While there is intuitive appeal to this idea, unfortunately there is not strong empirical evidence to support it. Most LMICs are also relatively low-resource environments, and again, intuitively, it seems likely that in such contexts there may be a tendency to focus on 'core business' rather than spread efforts across multisectoral actions. Furthermore, the skills required to support multisectoral action may be absent. Much of the writing about the governance of multisectoral collaborations in the global health field focuses on the capacity for joint action and the mechanisms and processes through which joint action occurs. Such papers flag the lack of resources to manage multisectoral collaborations, and even where resources are initially set aside to support a collaboration (as was the case with COCTU in Uganda), the difficulty of maintaining priority for collaboration and hence sustaining budgets over time. ${ }^{43}$ Lack of time dedicated by different sectoral partners to manage coordination processes is also a commonly identified challenge.

Case studies of multisectoral collaboration for health also identify a number of human resource challenges, including reliance on external consultants to facilitate collaborative processes and hence a failure to embed skills within organisations and develop effective networks. ${ }^{53}$ Staff rotation has also been observed as problematic, leading to a loss of continuity, although staff rotation within the civil service may also be a way to promote better understanding across different sectors. ${ }^{51}$

\section{Ideas}

Many of the contextual challenges described in papers about multisectoral action in LMIC speak to the lack of knowledge of stakeholders outside the health sector, about the scale of the problem, the feasibility of solutions and the benefits of collaboration. In Morocco, Tunisia and Mexico, policy-makers outside the health sector were found not to perceive obesity as a major public health problem. ${ }^{545}$ Such challenges may be compounded by the attitudes of many health sector stakeholders, who look to health services as the primary strategy to improve health, despite the established relevance of non-health service-based interventions. ${ }^{56}$

Many authors, frustrated by the lack of awareness of health issues by stakeholders in other sectors, call for greater education for such stakeholders to sensitise them to the benefits of multisectoral approaches. While in general, there are strong arguments for strengthening knowledge about the nature of the public health among the general population, including stakeholders in other sectors, it is likely unrealistic to expect such stakeholders to become highly engaged in public health debates, and in some cases, the problem may be less one of general awareness and more one of competing priorities, which would likely require different strategies to address. De Leeuw, ${ }^{1}$ reflecting on health policies and guidance regarding multisectoral collaboration, suggests that there is 'significant naiveté' and that 'most health professionals and scholars may also stand in the way of a realistic appraisal of the complex and competitive nature of integration efforts'. Certainly, there is a tendency in the health literature to view other sectors as providing instrumental opportunities to further the goals of the health sector. The Health in All Policies approach, ${ }^{57}$ for example, advocates systematically screening policy developments across other sectors to assess their potential implications for health and health equity, which could be seen as framing collaboration in a unidirectional fashion. If there are not obvious benefits to other sectors in engaging with health, ${ }^{52}$ then collaboration is unlikely to be sustainable.

For most 'wicked problems' that have multiple intersecting causes, the nature of the problem can be framed in very different ways. ${ }^{58}$ For example, obesity can be seen as a problem linked to the broader environment including factors such as lack of easy access to healthy foods and limited opportunities for exercise due to poorly designed urban infrastructure or security concerns. Alternatively, obesity may be seen as an individual health problem stemming from lack of knowledge about a healthy diet and weak executive function or self-control. These alternative framings of the problem, which are frequently politically or ideologically driven, lead to different policy responses. For example, the latter framing of obesity as an individual responsibility implies potentially simpler solutions that 
focus on health education and individual empowerment strategies, rather than more complex interventions such as changing the food system and urban environment that the former framing would suggest. Further, the environmental framing is likely to spur greater conflict and active resistance from certain powerful groups that may lose out from such an approach, including the food and automobile industries. Where there is a choice about how a public health problem can be framed, and much more manageable implications stemming from a particular framing, as well as limited incentives for a more ambitious truly multisectoral framing, it is easy to see why an individual responsibility framing persists. By contrast, other multisectoral challenges, such as emergent zoonotic diseases, are less easily framed as individual responsibilities, and while they may still spur some resistance (eg, opposition to the mass culling of birds in response to Avian influenza outbreaks in Vietnam), their multisectoral origins are likely to be less contested.

\section{OVERVIEW OF PAPERS IN THE SUPPLEMENT}

In this introductory paper, we have sought to identify some of the main challenges to approaching governance of multisectoral action for health, reflecting both on the need for greater theoretical and conceptual clarity, and the relatively sparse empirical evidence in this domain. The papers included in the rest of the supplement begin to address some of these gaps, although inevitably there is substantial further work that needs to be done.

We include two conceptual or theoretical papers. The first, by Emerson, ${ }^{59}$ builds on previously published work describing a framework for understanding collaborative governance and considers how this might be applied to multisectoral collaborations for health in LMIC. This framework considers (1) how contextual factors affect collaboration, (2) the drivers of collaboration, meaning what factors instigate collaboration, (3) collaboration dynamics, referring to the nature of ongoing interactions between different actors in different sectors and how these are progressively shaped by factors such as motivations and capacity and finally (4) outcomes, that is how collaboration affects the implementation of policies, programmes and health goals. Case studies of multisectoral collaboration for health in LMIC are used to illustrate the relevance of the framework. Bump ${ }^{60}$ focuses on the development of frameworks on nutrition governance, an archetypal multisectoral issue. Based on an extensive literature review, Bump observes how papers addressing governance of obesity differ significantly from those addressing governance of undernutrition and seeks to develop a synthetic governance framework that encompasses both aspects of nutrition.

Following this, we offer two case studies that illustrate the diversity of governance challenges faced in different settings and for different issues. Kanchanachitra et a $t^{61}$ describe the Thai experience with an asbestos ban that was heavily contested by industry. While the Thai Ministry of Public Health, in collaboration with other actors including civil society, managed to secure a Cabinet resolution banning chrysotile asbestos products, substantial power remained with implementing ministries particularly the lead implementers-the Ministry of Commerce and the Ministry of Industry-which failed to put the necessary protections in place. Through systematically analysing the power and interests of different stakeholders in this case, Kanchanachitra et al illustrate some of the challenges faced when there are fundamentally conflicting interests and speculate on how stronger pathways to implementation could have been developed. Our second case (Zaidi et al, ${ }^{62}$ ) analyses difference between the multisectoral governance of early childhood development and nutrition in Pakistan. By employing a comparative case study approach, Zaidi $e t$ $a l$ are able to compare the different trajectories of multisectoral efforts to address child undernutrition and early childhood development in Pakistan, with child undernutrition gaining considerable traction on the policy agenda, which early childhood development failed to do. Zaidi et al point to the importance of clear policy solutions, financial incentives for collaboration and a platform for ministerial coordination.

There are two concluding papers. The first, by Glandon et $a l l^{63}$ is derived from a separate project, which sought to identify research priorities related to multisectoral action for health. This paper draws on semistructured interviews, an overview of reviews and a ranking exercise to identify research priorities within this domain. While the project was initiated separately from this supplement and does not have an exclusive focus on governance, it offers some resonant conclusions, highlighting in particular the need for much greater conceptual and theoretical clarity as well as more robust empirical studies so as to address these issues in the context of LMIC. Finally, Rasanathan et a ${ }^{64}$ reflect on the policy implications of this supplement and put forward an agenda for future efforts to strengthen governance to enable multisectoral action for health, while also considering the support required to realise such an agenda.

\section{CONCLUSION}

Multisectoral action is central to the achievement of the SDGs and increasingly relevant across a broad swathe of global public health issues. While there is extensive literature from the perspective of specific disease or health conditions that implicitly addresses governance issues linked to multisectoral action in LMICs, there is very little explicit research or analysis in this space, and that which has been conducted rarely draws on relevant frameworks from the broader public policy and public administration, political economy or governance literature. Findings regarding multisectoral action for health from high-income countries undoubtedly yield insights for LMICs, but there also needs to be careful assessment of the transferability of findings in light of differing bureaucratic and political economy challenges.

Unfortunately, there is relatively limited evidence of the impact of multisectoral actions on outcomes. The few 
systematic reviews undertaken to explore this question ${ }^{656}$ have typically found only modest effects. Effects appear to be greater for collaborative interventions that are more proximal to the intended outcomes (ie, downstream interventions such as integrated service delivery mechanisms, as opposed to upstream interventions such as action on housing) ${ }^{65}$ There is also greater evidence to suggest impact on process outcomes versus public health outcomes. ${ }^{66}$ However, both of the cited reviews draw exclusively on studies from high-income countries. Moreover, the authors indicate that the quality of many studies in this field is low. Overall, it may be very challenging to measure the effects of multisectoral interventions that are frequently complex in nature and that impact health through multiple interrelated channels. Further, the quality of collaborations has rarely been investigated in a structured or systematic way. While there are approaches to assess collaboration, such as Himmelman's hierarchy of collaboration that distinguishes between networking (at the lowest level), cooperation, coordination and collaboration (at the highest) ${ }^{67}$ and a number of formal tools to assess the quality of partnerships (such as the Nuffield Partnership Assessment Tool and the Verona Benchmark), ${ }^{68}$ these approaches do not appear to have been applied in LMIC contexts.

This supplement seeks to stimulate policy-makers, practitioners and researchers to explicitly bring to bear some of the relevant frameworks, strategies and tools to strengthen governance of multisectoral action and also to evaluate these efforts. While, as we have discussed here, there will inevitably be differences across country context and across different types of multisectoral challenges, depending, for example, on the extent of alignment of interests between sectors, it is important to move beyond scattered case studies, towards more systematic assessments of how to build capacity for governing multisectoral action and how to approach collaborations in a way that is more likely to lead to sustained success. Practical tools to assist policy-makers in LMICs, in navigating these complexities are also needed. The recent paper by Harris and Viliani offers one specific, practical approach. ${ }^{69}$

In conclusion, achievement of the SDGs-and not just the health SDG, but other SDGs too-depends on supporting innovation and learning around the governance of multisectoral action, to strengthen individuals, organisations and systems for multisectoral action and to provide clear and prioritised guidance to stakeholders. Much of the health-related literature on multisectoral action, particularly that from LMIC, takes the form of case studies, frequently without clear, underlying conceptual frameworks and often conducted in disease or health condition-specific siloes. While there is a rich body of work in other disciplines on multisectoral collaboration, more needs to be done to adapt these ideas and apply them to multisectoral action for health. Further, research methods for empirical work in this field and metrics for assessing multisectoral action and its effects need to be better developed and more widely discussed and agreed. While the papers presented here aim to prompt further thought and discussion about the governance of multisectoral action for health, we acknowledge that they serve primarily as a starting point, hopefully to focus greater attention and more careful research on this issue in the future.

Contributors This paper was conceived and initially discussed by all three authors. SB wrote the first draft. DG and KR discussed the draft, made edits and comments. SB revised based on inputs. All authors reviewed and approved the final version of the manuscript.

Funding Initial work on this study was funded by the Rockefeller Foundation, with additional support from the UK Department for International Development under Grant No HRPC09 Future Health Systems: Delivering Effective Health Services. Publication was supported by Rockefeller Foundation via Unicef.

Competing interests None declared.

Patient consent Not required.

Provenance and peer review Not commissioned; externally peer reviewed.

Data sharing statement № additional data are available.

Open access This is an open access article distributed in accordance with the Creative Commons Attribution Non Commercial (CC BY-NC 4.0) license, which permits others to distribute, remix, adapt, build upon this work non-commercially, and license their derivative works on different terms, provided the original work is properly cited, appropriate credit is given, any changes made indicated, and the use is non-commercial. See: $\mathrm{http} / / /$ creativecommons.org/licenses/by-nc/4.0

\section{REFERENCES}

1. de Leeuw E. Engagement of sectors other than health in integrated health governance, policy, and action. Annu Rev Public Health 2017;38:329-49.

2. Tangcharoensathien V, Srisookwatana O, Pinprateep P, et al. Multisectoral actions for health: challenges and opportunities in complex policy environments. Int $J$ Health Policy Manag 2017;6:359-63.

3. Nilsson M, Griggs D, Visbeck M. Policy: Map the interactions between sustainable development goals. Nature 2016;534:320-2.

4. Nunes AR, Lee K, O'Riordan T. The importance of an integrating framework for achieving the sustainable development goals: the example of health and well-being. BMJ Glob Health 2016;1:e000068.

5. Marmot M. Social determinants of health inequalities. Lancet 2005;365:1099-104.

6. Marmot M, Friel S, Bell R, et al. Closing the gap in a generation: health equity through action on the social determinants of health. Lancet 2008;372:1661-9.

7. Rasella D, Aquino R, Santos CA, et al. Effect of a conditional cash transfer programme on childhood mortality: a nationwide analysis of Brazilian municipalities. Lancet 2013;382:57-64.

8. Atun R, de Andrade LO, Almeida G, et al. Health-system reform and universal health coverage in Latin America. Lancet 2015;385:1230-47

9. Shibuya K, Ciecierski C, Guindon E, et al. WHO framework convention on Tobacco control: development of an evidence based global public health treaty. BMJ 2003;327:154-7.

10. Staton C, Vissoci J, Gong E, et al. Road traffic injury prevention initiatives: a systematic review and metasummary of effectiveness in low and middle income countries. PLoS One 2016;11:e0144971.

11. Rasanathan K, Bennett S, Atkins V, et al. Governing multisectoral action for health in low- and middle-income countries. PLoS Med 2017;14:e1002285.

12. UNESA, UNDP, and UNESCO. Governance and development: thematic think piece, in UN system task team on the post-2015 un development agenda, 2012.

13. World Health Organization. Health systems strengthening glossary, 2011.

14. Axelsson R, Axelsson SB. Integration and collaboration in public health-a conceptual framework. Int $J$ Health Plann Manage 2006;21:75-88.

15. Ansell C, Gash A. Collaborative governance in theory and Practice. $J$ Public Adm Res Theory 2008;18:543-71.

16. Marten R, Hawkins B. Stop the toasts: the global fund's disturbing new partnership. Lancet 2018;391:735-6.

17. Moodie R, Stuckler D, Monteiro C, et al. Profits and pandemics: prevention of harmful effects of tobacco, alcohol, and ultraprocessed food and drink industries. Lancet 2013;381:670-9. 
18. Johnston LM, Finegood DT. Cross-sector partnerships and public health: challenges and opportunities for addressing obesity and noncommunicable diseases through engagement with the private sector. Annu Rev Public Health 2015;36:255-71.

19. Besley T, Persson T. State capacity, conflict and development. Econometrica 2010;78:1-34.

20. Brinkerhoff DW, Bossert TJ. Health governance: principal-agent linkages and health system strengthening. Health Policy Plan 2014;29:685-93.

21. Vian T. Review of corruption in the health sector: theory, methods and interventions. Health Policy Plan 2008;23:83-94.

22. Ruckert $A$, Labonté R. Public-private partnerships (ppp s) in global health: the good, the bad and the ugly. Third World $Q$ 2014;35:1598-614.

23. Reich MR. Public-private partnerships for public health. Nat Med 2000;6:617-20.

24. Swanson RC, Atun R, Best A, et al. Strengthening health systems in low-income countries by enhancing organizational capacities and improving institutions. Global Health 2015;11:5.

25. Pollitt C. Joined-up government: a survey. Political Studies Review 2003;1:34-49.

26. O'Flynn J, Blackman D, Halligan J. Crossing boundaries in public management and policy: the international experience. Routledge critical studies in public management. London and New York: Routledge, 2014.

27. Bryson JM, Crosby BC, Bloomberg L. Public value governance: moving beyond traditional public administration and the new public management. Public Adm Rev 2014;74:445-56.

28. Emerson $\mathrm{K}$, Nabatchi T. Collaborative governance regimes. Washington DC: Georgetown University Press, 2015: 279.

29. Burnside C, Dollar D. Aid, policies, and growth. Am Econ Rev 2000;90:847-68.

30. Abimbola S, Negin J, Martiniuk AL, et al. Institutional analysis of health system governance. Health Policy Plan 2017;32:1337-44.

31. Siddiqi S, Masud TI, Nishtar S, et al. Framework for assessing governance of the health system in developing countries: gateway to good governance. Health Policy 2009;90:13-25.

32. Gilson L, Lehmann $U$, Schneider H. Practicing governance towards equity in health systems: LMIC perspectives and experience. Int $J$ Equity Health 2017;16:171.

33. Ciccone DK, Vian T, Maurer L, et al. Linking governance mechanisms to health outcomes: a review of the literature in low- and middleincome countries. Soc Sci Med 2014;117:86-95.

34. McQueen DV. Intersectoral governance for health in all policies: structures, actions and experiences, T.E.O.o.H.S.a. policies. WHO Regional Office for Europe: Copenhagen, 2012.

35. Kickbusch I, Gleicher D. Governance for health in the 21st Century. World Health Organization, Europe: Copenhagen, 2012.

36. Dodgson R, Lee K, Drager N. Global health governance: a conceptual review 2002.

37. Youde J. Global health governance. Cambridge: Polity Press, 2012.

38. McInnes C, Kamradt-Scott A, Lee K, et al. Framing global health: the governance challenge. Glob Public Health 2012;7-83-94.

39. Lee K. Globalization, global governance, and the social determinants of health: a review of the linkages and agenda for action, G.a.H.K.N. WHO Commission on the Social Determinantsof Health. University of Ottawa: Ottawa, 2007.

40. Ostrom E. Background on the Institutional Analysis and Development Framework. Policy Studies Journal 2011;39:7-27.

41. Harris D, Booth D. Applied political economy analysis: five practical issues. London: ODI, 2013.

42. Hall PA. Comparative politics: rationality, culture, and structure. In: Lichbach MI, Zuckerman AS, eds. The role of interests, institutions and ideas in the comparative political economy of the industrialized nations. Cambridge, UK: Cambridge University Press, 1997: 174-207.

43. Okello AL, Bardosh K, Smith J, et al. One health: past successes and future challenges in three African contexts. PLoS Negl Trop Dis 2014;8:e2884.

44. Levinson J, Balarajan Y. Addressing malnutrition multisectorally: what have we learned from recent international experience? In MDG Achievement Fund. New York: UNICEF, 2013: 52.

45. Acosta AM. Examining the political, institutional and governance aspects of delivering a national multi-sectoral response to reduce maternal and child malnutrition: Brazil country report, in analyzing nutrition governance. Institute for Development Studies: Falmer, Sussex, 2011.
46. Solon FS. Good governance for nutrition in the philippines: elements, experiences, and lessons learned. Food Nutr Bull 2006;27:343-52.

47. Hoe C, Rodriguez DC, Üzümcüoğlu Y, et al. "Quitting like a turk:" how political priority developed for tobacco control in Turkey. Soc Sci Med 2016;165:36-45.

48. Da Costa S, Goldfarb L. Government leadership in tobacco control: Brazil's experience. In: de Beyer J, Brigden L, eds. Tobacco control policy: strategies, successes and setbacks. Washington DC: World Bank, 2003.

49. Smith J, Taylor EM, Kingsley P. One world-one health and neglected zoonotic disease: elimination, emergence and emergency in Uganda. Soc Sci Med 2015;129:12-19.

50. Nicholson-Crotty S. Bureaucratic competition in the policy process. Policy Studies Journal 2005;33:341-61.

51. Stead D. Institutional aspects of integrating transport, environment and health policies transport policy 2008;15:139-48.

52. Garrett J, Basset L, Levinson E, et al. Principles and conceptual model for working multisectorally. In: Garrett J, Nataliccio M, eds. Working multisectorally in nutrition : principles, practices, and case studies. Washington DC: International Food Policy Research Institute, 2011.

53. Hendriks AM. Interventions to promote an integrated approach to public health problems: an application to childhood obesity. $J$ Environ Public Health 2012. 2012;913236.

54. Holdsworth M, El Ati J, Bour A, et al. Developing national obesity policy in middle-income countries: a case study from North Africa. Health Policy Plan 2013;28:858-70.

55. Pérez-Ferrer $\mathrm{C}$, Lock K, Rivera JA. Learning from international policies on trans fatty acids to reduce cardiovascular disease in lowand middle-income countries, using Mexico as a case study. Health Policy Plan 2010;25:39-49.

56. Fawcett S, Schultz J, Watson-Thompson J, et al. Building multisectoral partnerships for population health and health equity. Prev Chronic Dis 2010;7:A118.

57. Kickbusch I, Buckett K. Implementing health in all policies: Adelaide 2010. Rundle Mall: Department of Health, Government of South Australia, 2010: 184.

58. Hunter DJ. Leading for health and wellbeing: the need for a new paradigm. J Public Health 2009;31:202-4.

59. Emerson K. Collaborative governance of publichealth in LMICs: lessons from researchin public administration. BMJ Global Health 2018. In press. doi:10.1136/bmjgh-2017-000381.

60. Bump J. Undernutrition, obesity and governance: a unified framework for upholding theright to food. BMJ Global Health 2018. In press. doi:10.1136/bmjgh-2018-000886.

61. Kanchanachitra C, Tangcharoensathien V, Patcharanarumol W, et al. Multisectoral governance for health:challenges in implementing a total banon chrysotile asbestos in Thailand. BMJ Global Health 2018. In Press. doi:10.1136/bmjgh-2017-000383.

62. Zaidi S, Bhutta Z, Hussain SS, et al. Multisector governance for nutrition and early childhood development:overlapping agendas and differing progress in Pakistan. BMJ Global Health 2018. In press. doi:10.1136 bmjgh-2017-000678.

63. Glandon D, Meghani A, Jessani N, et al. Identifying health policy and systems research priorities on multisectoral collaboration for health in low-income and middle-income countries. BMJ Global Health 2018. In press. doi:10.1136/bmjgh-2018-000970.

64. Rasanathan K, Atkins V, Mwansambo C, et al. Governing multisectoral action for health in low-income and middle income countries: an agenda for the way forward. BMJ Global Health 2018. In press. doi: 10.1136/bmjgh-2018-000890.

65. Ndumbe-Eyoh S, Moffatt $\mathrm{H}$. Intersectoral action for health equity: a rapid systematic review. BMC Public Health 2013;13:1056.

66. Roussos ST, Fawcett SB. A review of collaborative partnerships as a strategy for improving community health. Annu Rev Public Health 2000;21:369-402.

67. Himmelman A. Collaboration for a change: definitions, decisionmaking models, roles, and collaboration process guide. Minneapolis: Himmelman Consulting, 2002.

68. Halliday J, Asthana S, Richardson S. Evaluating partnerships: the role of formal assessment tools. Evaluation 2004;10:285-303.

69. Harris P, Viliani F. Strategic health assessment for large scale industry development activities: an introduction. Environ Impact Assess Rev 2018:68:59-65. 